\title{
Current Situation and Countermeasure of Modern Agriculture Development in Northeast China
}

\author{
Wenxin Liu, Xiuli He \\ Regional Development Research Center of Northeast China, Northeast Institute of Geography and Agroecology, Chinese \\ Academy of Sciences, Changchun, China \\ Email: liuwx@iga.ac.cn, hexiuli@iga.ac.cn
}

How to cite this paper: Liu, W.X. and He, X.L. (2018) Current Situation and Countermeasure of Modern Agriculture Development in Northeast China. Open Access Library Journal, 5: e4922.

https://doi.org/10.4236/oalib.1104922

Received: September 18, 2018

Accepted: October 8, 2018

Published: October 11, 2018

Copyright $(\odot) 2018$ by authors and Open Access Library Inc.

This work is licensed under the Creative Commons Attribution International License (CC BY 4.0).

http://creativecommons.org/licenses/by/4.0/

(c) (7) Open Access

\begin{abstract}
Since the implementation of the revitalization strategy, Northeast China has undergone great changes in safeguarding the national grain security and confronted with many problems in developing the modern agriculture. It is necessary to find out measures to promote the development of modern agriculture. The volume of grain production in Northeast China accounts for $19.27 \%$ of the whole country and is still on the rise. The proportion of grain crops increases rapidly, and the proportion of non-grain crops continues to decline. The structure of grain crops tends to be dominated by maize, rice, and soybean. The planting structure of the three major grain crops has changed significantly, and maize has an absolute advantage. Confronted with the problems of agricultural science and technology level, infrastructure, market circulation, system and mechanism, Northeast China should take the road of modern agricultural development with local characteristics through regulating the production structure, implementing large-scale operation, building the whole industry chain, making scientific and technological innovation, and preventing risks.
\end{abstract}

\section{Subject Areas \\ Human Geography}

\section{Keywords}

Modern Agricultural Development, Grain Production Capacity, Countermeasure, Northeast China

\section{Introduction}

China's agriculture takes on significant characteristics of a big country, such as 
large scale of supply and demand, enormous regional differences, and large agricultural population; besides, in the process of promoting the development of modern agriculture, China is faced with complex internal and external pressures, which increases difficulty in the transformation and development of agriculture [1]. With regard to the development of modern agriculture in the process of industrialization in developing countries, William Arthur Lewis proposed the Dualistic Development Model and stated that the labor transfer shifts agricultural surplus to the industrial sector to achieve agricultural modernization; Theodore William Schultz, on the basis of the idea of "transformation of traditional agriculture", stressed that it is required to improve the agricultural development quality and level through technological progress and improvement of the quality of agricultural human resources [2]. Over the past 30 years of reform and opening up, China's economic development basically followed this Dualistic Development Model, but such "extensional" and "supplementing industry by agriculture" expansion model fails to promote agriculture to realize modernization along with the industrial development. The "connotation" development model proposed by Theodore William Schultz has important reference significance at the present stage.

Many scholars have carried out qualitative evaluation and quantitative calculation of China's modern agriculture and agricultural modernization level from different dimensions, and have obtained rich research results in following aspects: 1) the connotation, development stage and constraints of modern agriculture [3] [4];2) the construction of the measurement indicator system of modern agricultural development level [5] [6] [7]; 3) the calculation of the development level of agricultural modernization at different time and space scales [8] [9]; 4) operation modes, operation entities, and development path of modern agriculture [10] [11] [12]. At present, there are relatively few research results about the analysis of modern agricultural development trend, problems and countermeasures in typical agricultural areas. Northeast China is an important commodity grain base in China and has an important strategic position for safeguarding national grain security [13] [14]. Since the implementation of the strategy of revitalizing the old industrial bases in Northeast China in 2003, the state has issued a series of documents, which greatly promoted the development of modern agriculture in Northeast China. The annual growth rate of grain yield in Northeast China reaches 3.99\%, and the proportion to the whole country rose from $14.56 \%$ to $19.27 \%$, making Northeast China become a major contributor to the increase in China's grain yield. In addition, there are many problems in the grain production of Northeast China, such as extensive expansion, unreasonable planting structure, high pressure of maize stock, serious ecological and environmental damage, dramatic impact of international grain price, rise of grain costs and drop of comparative benefits, and backward agricultural infrastructure [15] [16] [17] [18]. On the basis of changes in foreign and domestic agricultural production and strategic demands of comprehensively revitalizing the old industrial bases in Northeast China, we discussed the changes in the position of Northeast 
China in the whole country, analyzed main problems in the development of modern agriculture, and came up with recommendations for sustainable development of agriculture in Northeast China, in order to provide a scientific reference for Northeast China developing modern agriculture with local characteristics.

\section{Current Situations of Modern Agricultural Development in Northeast China}

\subsection{Strong growth of Grain Production, and Enhancement of the Capability of Safeguarding National Grain Security}

Since the founding of New China, the grain yield of the three northeastern provinces has increased from 14.418 million $t$ to 119.735 million $t$ in 2015 , increasing by 8.3 times, which laid a strategic position for the three northeastern provinces in the national grain security. The changes in the proportion of grain yield to the whole country experienced three stages. 1) 1949-1990: except in 1949 and in 1990, the proportion was $13 \%$; in other years, the proportion was lower than this value and there was one time of obvious rise and fall every 2 - 3 years [19]. 2) 1991-2003: the proportion lingered about $12.6 \%-14.6 \%$, and this stage was stable with fluctuation. 3) 2004-2015: the proportion grew year by year; in 2016, the total grain yield of Northeast China reached 11.8763 million $t$, and the proportion was up to $19.7 \%$. In the past ten years, the grain production capacity and stability in Northeast China have been at historically high level, thus providing a higher level of guarantee for national grain security (Figure 1).

\subsection{Forming of Regional Superior Crops with the Yield of Maize and Soybean Accounting for $1 / 3$ of the Whole Country}

In 2016, the yield of maize, rice and beans in the three northeastern provinces accounted for $62.50 \%, 28.60 \%$ and $5.20 \%$ of the total grain yield in Northeast China, respectively; the planting area of maize, rice and beans in the three northeastern provinces accounted for $42.0 \%, 25.8 \%$ and $24.5 \%$ of the total grain planting area in Northeast China, respectively, and Northeast China has formed the production capacity pattern with maize, rice, and soybean as the main crops. From the internal structure of grain, the increase in maize and rice is the main reason for the increase in total grain yield in Northeast China. In 2003-2016, the

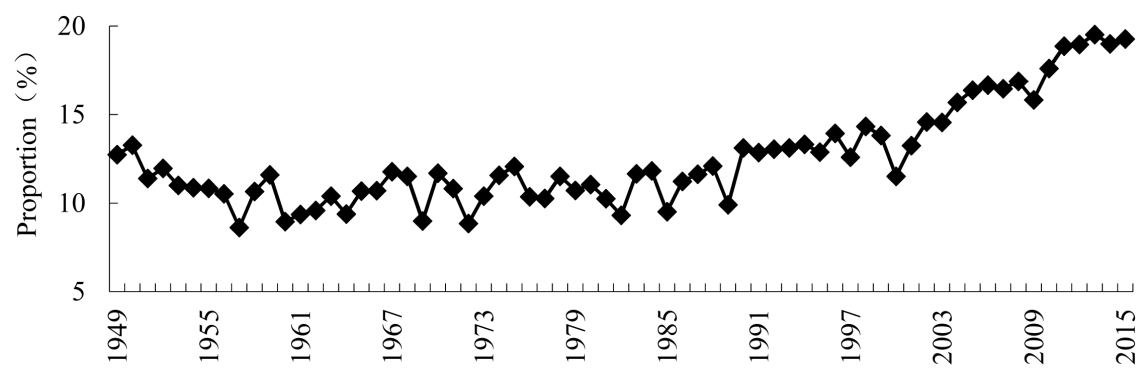

Figure 1. Changes in the proportion of grain yield of the three northeastern provinces to the whole country in 1949-2014. 
maize yield of the three northeastern provinces increased from 33.767 million $t$ to 74.26 million $t$, with an average annual growth rate of $5.79 \%$, and the percentage to the whole country increased from $29.15 \%$ to $33.8 \%$; in the same period, the rice yield increased from 14.716 million $t$ to 33.939 million $t$, with an average annual growth rate of $6.15 \%$, and the percentage to the whole country increased from $9.16 \%$ to $16.4 \%$. In comparison, the yield of beans in Northeast China, affected by the international market, declined from 8.156 million $t$ to 6.157 million $\mathrm{t}$ in the same period, with the annual decline of $1.98 \%$, and the percentage to the whole country dropped from $38.34 \%$ to $35.6 \%$. According to the overall situation of the percentage to the whole country, both the maize and the soybeans exceeded $30 \%$, so they are crops with significant advantages (Table 1).

\subsection{Significant Changes in Grain and Industrial Crop Structure and Internal Structure of Grain Crops}

In 2003-2016, the sown area of crops in the three northeastern provinces increased from 17.74421 million ha to 22.167 million ha, of which grain crops increased from 14.4404 million ha to 20.0578 million ha, while the sown area of industrial crops and other crops (hereinafter referred to as non-grain crops) decreased from 3.30381 million ha to 2.1092 million ha. The percentage of sown area of non-grain crops to that of crops decreased from $18.62 \%$ to $9.52 \%$, and the share to crops dropped by 10 percentage points (Figure 2).

In 2003-2016, the sown area of three main staple crops (maize, rice and soybean) in Northeast China increased from 12.2479 million ha to 19.2031 million ha, and the proportion to the sown area of grain crops increased from $84.8 \%$ to

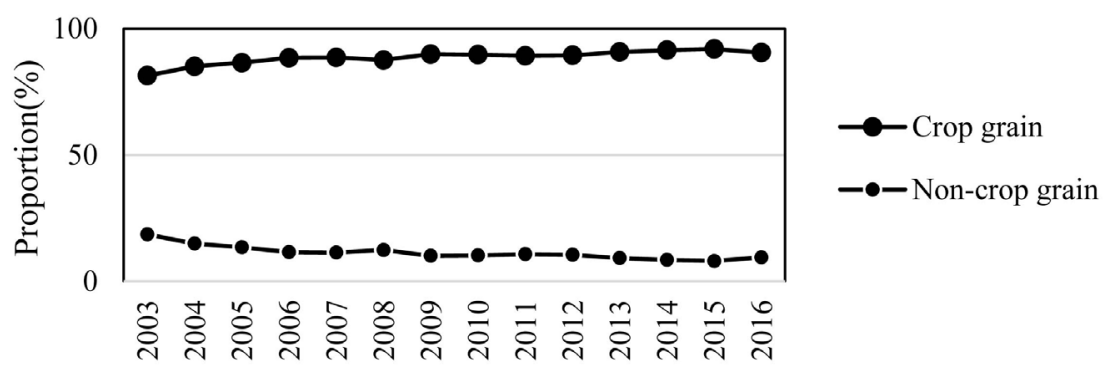

Figure 2. Changes in the proportion of grain crops and non-grain crops in the three northeastern provinces (\%).

Table 1. Changes in the yield of grain crops in the three northeastern provinces and their proportion to the country $\left(10^{4} \mathrm{t}, \%\right)$

\begin{tabular}{ccccccccc}
\hline & \multicolumn{9}{c}{ Output } & \multicolumn{4}{c}{ Proportion } \\
\cline { 2 - 8 } & Grain & Rice & Maize & beans & Grain & Rice & Maize & beans \\
\hline 2003 & 6270.20 & 1471.6 & 3376.7 & 815.6 & 14.56 & 9.16 & 29.15 & 38.34 \\
2005 & 7927.01 & 2065.0 & 4534.8 & 944.3 & 16.38 & 11.43 & 32.54 & 43.77 \\
2010 & 9620.70 & 2870.0 & 5478.9 & 732.0 & 17.60 & 14.66 & 30.91 & 38.60 \\
2015 & 11973.50 & 3297.5 & 7753.4 & 501.0 & 19.27 & 15.84 & 34.52 & 31.52 \\
2016 & 11876.30 & 3394.0 & 7426.0 & 615.7 & 19.27 & 16.39 & 33.82 & 35.58 \\
\hline
\end{tabular}


95.74\%, while the proportion of wheat, sorghum, millet and potato and other coarse grain crops became smaller and smaller (the sum was less than 5\%). In the same period, the gap between the sown area of grain crops and three staple crops was gradually widening from 10.05544 million ha to 18.3482 million ha. This indicates that since 2003, the total sown area of maize, rice and soybean in the three northeastern provinces has nearly doubled, which is the strategic choice of agricultural production subjects based on factors such as resources, market, and price (Figure 3).

Specifically, the three main staple crops have formed a planting pattern dominated by maize. Since the maize sown area accounted for $50 \%$ of the grain sown area in 2011, the proportion has exceeded $60 \%$ in just four years, and the maize sown area has risen rapidly, which is the root cause of the structural problem of grain and also an important motivation for the issuing of policies such as regulating the maize planting structure and temporary storage of maize in "Sickle Bend Region" (from northeast to north China-southwest-northwest, like the sickle bend in the map) (Figure 4).

\section{Analysis on the Prominent Problems Faced by Modern Agricultural Development in Northeast China}

\subsection{Imperfect Agricultural Science and Technology Support System and Low Contribution of Per Unit Area Yield to Grain Production Increase}

The agricultural science and technology innovation ability is weak. In the fine

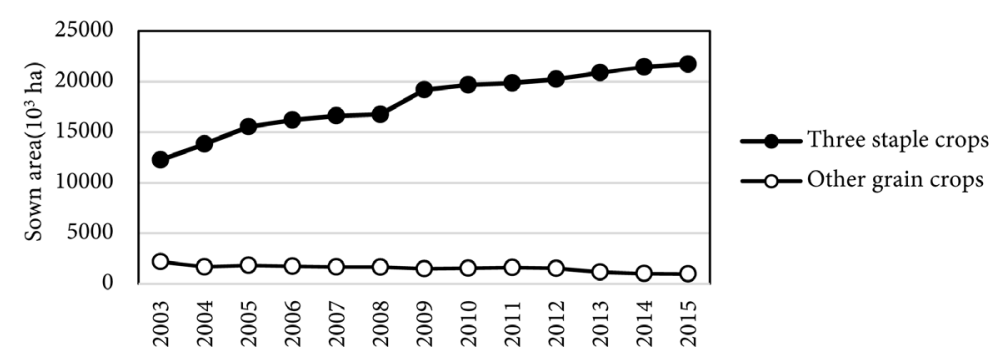

Figure 3. Changes in the sown area of three staple crops and other grain crops in the three northeastern provinces $\left(10^{3} \mathrm{ha}\right)$.
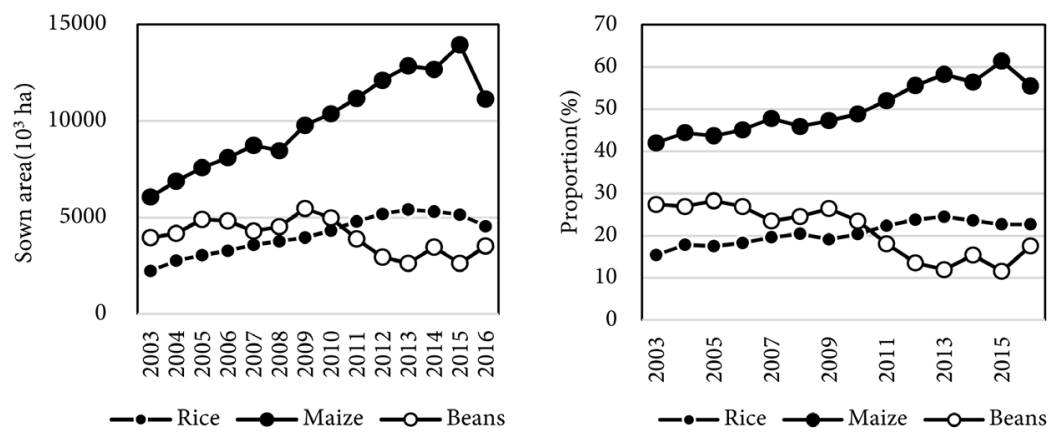

Figure 4. Changes in main staple crops in the three northeastern provinces. Left: the sown area $\left(10^{3} \mathrm{ha}\right)$; Right: proportion of sown area (\%). 
seed breeding, high-yield cultivation, agricultural water saving, agricultural ecological environment construction, animal and plant disease prevention and control, green grain storage, green grain storage, and grain purchasing and storage rapid detection technology, there is still no effective technology integration and innovation system, promotion system, and related management system, so the driving of agricultural science and technology to grain production increase and internal structural adjustment is limited. The proportion of grain yield in the three northeastern provinces has increased year by year, and the rapid increase of sown area is a key contributor. Over the past ten years, the grain yield of the three northeastern provinces has increased by more than $45 \%$, and the grain sown area and the per unit area yield have increased by $29.4 \%$ and $12.4 \%$, respectively. The per unit area yield contributed little to the improvement of grain production capacity. In addition, Heilongjiang Province is the largest contributor to the grain production of the three northeastern provinces, and its annual grain production capacity and sown area accounted for $54.2 \%$ and $63.3 \%$ of the three provinces, while level of per unit area yield was equivalent to $85.4 \%$ of the three provinces, and the average level of three provinces was $5 \%$ lower than the national average level in the same period. Therefore, increasing the per unit area yield will be an effective way to promote the increase of grain production.

\subsection{Backward Agricultural Infrastructure Construction and Significant Regional Difference of Mechanization Level}

The construction of water conservancy projects and supporting irrigation areas is slow, the system and mechanism of water conservancy projects are not perfect, and the county-level farmland water conservancy planning is not well made. As a result, the farmland irrigation water support capacity in Northeast China is weak, and the proportion of medium-and-low-yielding fields is relatively high. The effective irrigated area in the three northeastern provinces accounted for $35.63 \%$ of the farmland area, about 16.5 percentage points lower than the national average level. This is a key contributor to the fluctuation of grain production level and weak capacity of guaranteeing grain ration production in Northeast China. As one of the regions with the highest level of agricultural mechanization in China, Northeast China has typical advantages of total power of agricultural machinery. Such advantages offset the huge differences between the regions. 1) At provincial level: in the past ten years, the total power of agricultural machinery in three northeastern provinces (Heilongjiang, Jilin, and Liaoning) grew by 2.31 times, 1.98 times and 1.50 times respectively. Among three provinces, total growth rate of Liaoning was lower than that of the other two provinces and lower than the national average. 2) At county level: A study of 40 county-level units in Jilin Province shows that the proportion of area ploughed by tractors and area sown by machines in 31 and 34 counties and cities is lower than the provincial average. 


\subsection{Loss of Advantages of Some Commodity Grain Bases and Imperfect Market Circulation System}

The construction of commodity grain bases in Northeast China has undergone a process from key distribution, scattered distribution, then to centralized distribution. In space, commodity grain bases expand from the central plain to the eastern mountain areas and the western grassland areas, showing a balanced distribution. However, due to large number of base counties, the effective investment and the overall support of the state are inadequate, and the fund guarantee system is not well established. At present, among the built commodity grain base counties, 82,71 , and 74 counties have main indicators such as the total grain yield, per capita grain yield, and per unit area yield exceeding the average level of three northeastern provinces respectively, accounting for about $70 \%$ of all bases, indicating that there have been great changes in the grain production advantages or the agriculture-dominated industrial structure in some commodity grain base counties [20]. In the process of commodity grain transportation, the northeastern national level commodity grain base counties generally lack specialized grain handling facilities and supporting grain reserve depot; besides, the development of sea and land transportation network lags behind, and the transportation capacity of agricultural products is generally weak and restricts the shipping of the grain from north to south to a certain extent [21].

\subsection{Multiple Constraints on the Formation and Development of Modern Agricultural Management System}

Although the state has issued many support policies for new large-scale land management entities such as large professional households, family farms and farmers' professional cooperatives, there are still many factors restricting the development of new business entities in the Northeast China. For farmers transferring out land, the restrictive factors include the limited ability of accepting the secondary and tertiary industries, imperfect household registration and social security system, weak non-agricultural employment ability of rural labors, and as high as $80 \%$ of farmers' income coming from the household operating income. These factors increase the dependence of farmers on the farmland. For farmers transferring in land, the restrictive factors include imperfect land circulation system, backward rural financial development, and short supply of credit to farmers with scale operation, as well as imperfect agricultural risk security mechanism. In addition, the matching degree between regional cultivated land resources and rural population distribution pattern also affects the large-scale operation of cultivated land to a certain extent. The spatial distribution of high quality cultivated land resources and population intensity is high, and the slow transfer rate of farmers and higher of higher the circulation price will restrict the large-scale operation of cultivated land. 


\section{Countermeasure for Promoting the Development of Modern Agriculture in Northeast China}

\subsection{Consolidating the Fundamental Position of Agriculture and Promoting the Coordinated Development between Grain Crops, Industrial Crops, and Forage Crops, and between Agriculture and Animal Husbandry}

It is recommended to continue to maintain the strategic position of Northeast China as an important commodity grain base and animal husbandry production base in China, and to give play to the geographical advantages of "Golden Maize Belt", "Golden Rice Belt" and "Hometown of Black Soil". Under the premise of moderately maintaining indicators such as per capita grain production, grain commodity rate, and grain yield, it is recommended to pay attention to the industrial base according to the spatial distribution rules of agricultural resources, and give priority to the development of leading products and characteristic products with outstanding comparative advantages, to form distinct industrial distribution of modern agriculture suitable for market demands and consistent with resource endowments. Besides, it is recommended to respect the natural conditions in Northeast China and the long-term grain crop dominated planting structure, strengthen guidance and orderly progress, and adhere to scientific and rational principles to solve the problems of "where, who, what and how adjust". Specifically, Northeast China can adjust the agricultural production structure in combination with relevant national policy recommendations and local development situations, adhere to the principles of "government guidance, market orientation, farmer voluntariness, and social participation", change to plant soybeans, rice, industrial crops, forage and silage maize, fresh maize and vegetables, and edible fungi, to gradually form the modern agricultural production and operation model combining grain and forage, integrating agriculture and animal husbandry, and focusing on circular development.

\subsection{Accelerating the Rural Land Circulation and Promoting the Scale Operation of Agriculture}

It is recommended to actively guide and encourage the masses through many forms to circulate rural land in a rational and orderly manner on the voluntary, compensated, and lawful principles, develop many types of planting and breeding bases, and give play to the model role of large scale operating organizations such as family farms and farmers' cooperatives to decentralized operating farmers. For example, with reference to experience and practice of typical land circulation models in China, such as "confirming rights and endowing functions" model of Chengdu in Sichuan Province, "share + cooperation" model of Ningyang in Shandong Province, "mortgage of land contractual management rights" model of Sanming in Fujian Province, "public auction of land contractual management rights" model of Qinyang in Henan Province, "family farm" model of Songjiang in Shanghai, "land trust" model of Shaoxing in Zhejiang Province, 
"land credit cooperative" model of Pingluo in Ningxia Hui Autonomous Region, "joint agricultural management" model of Chongzuo in Sichuan Province, Northeast China should explore and summarize the scale of operation patterns suitable for the characteristics of local agricultural production and the organizational structure of farmers, and promote moderate scale operations. It is recommended to cultivate new agricultural business entities such as large professional households, family farms and farmers' professional cooperatives, and gradually form a new type of agricultural management system based on household contract management and supplemented by other organizational forms, and develop various forms of agricultural scale management and socialized services, to guarantee national grain security and sound development of agriculture [22].

\subsection{Strengthening the Construction of Whole Industry Chain for Agriculture and Enhancing the Guidance of Agricultural Production in Processing and Consumption Links}

It is recommended to improve the vertical organization of agricultural production, extend the agricultural industry chain, integrate agricultural production, processing, and sales into a more compact community of shared interests, and give play to multiple functions of the community in circulation and production fields, to transmit the changes in the downstream market of the supply chain to the upstream agricultural production, and establish consumption-oriented agricultural industrial system. Relying on grain orders, Northeast China can establish a whole industry chain development model integrating planting, purchasing and storage, processing, and marketing, strengthen the construction of hardware facilities for processing, warehousing and logistics of agricultural products, set up service platforms for test and inspection, and information processing, so as to effectively promote efficiency and performance conversion of superior crops such as rice, maize, and soybean in Northeast China. Since many enterprises are small and medium-sized processing enterprises, it is recommended to cultivate provincial and city level leading enterprises in the grain processing field, raise the conversion ability of leading enterprises to regional agricultural products, cultivate clusters of small and medium sized enterprises, and give play to the cooperative effect and scale effect of agricultural industrial clusters based on raw material supply advantages of production areas of agricultural products.

\subsection{Strengthening Infrastructure Construction and Technological Innovation, to Comprehensively Promote the Optimization and Upgrading of Agricultural Production Structure}

It is recommended to strengthen the construction of rural productive infrastructure, formulate support policies for specific types of agricultural production areas, and improve agricultural production capacity through raising the hardware level of production areas. Besides, it is recommended to promote the construction of water conservancy projects, improve large and medium sized ma- 
chinery, upgrade the level and efficiency of agricultural mechanization in the Northeast Plain, and remove restraints faced in the regulation of agricultural production element input structure and planting structure, to provide basic conditions and equipment support for regulating agricultural production structure and shifting to the production of industrial crops with high added value. In addition, it is recommended to increase the conversion rate of agricultural scientific research achievements, promote the close integration of agricultural scientific research achievements and agricultural production, and enhance the market competitiveness of modern agriculture. Finally, it is recommended to give play to the role of the government in the extension of scientific and technological innovation, increase the investment in scientific research for the cultivation of fine seeds, planting and breeding techniques and fine and deep processing of agricultural special products, encourage universities and research institutes to carry out agricultural technical services, and provide accurate guidance for grassroots agricultural technology extension service organizations, and provide technical support for regulation of agricultural production structure.

\subsection{Strengthening Risk Prevention to Reducing the Probability of Various Risks in Modern Agricultural Development}

Apart from natural risks, modern agricultural development is also affected by many factors such as market price fluctuation, scientific and technological development level, business decision-making philosophy, contract performance degree, and farmers' quality level. Thus, it is necessary to strengthen the awareness and level of management institutions and agricultural production operators in dealing with various risks, to effectively prevent risks. It is recommended to strengthen the responsibilities of government in agricultural production, including providing comprehensive information services, financial support, scientific and technological services, legal services, climate and disaster forecasting services; establishing agricultural risk monitoring and early warning systems, collecting and collating agricultural risk information, and establishing agricultural information monitoring networks at provincial, city, and county levels, and providing agricultural risk warning using modern information technology; expanding and improving the scope of agricultural insurance business, providing as comprehensive as possible subsidies for crop insurance business related to national economy and people's livelihood; undertaking targeted vocational and technical training to improve the scientific and technological quality of farmers, strengthen farmers' analytical ability and production decision-making ability in the agricultural product market, and raise the ability of agricultural producers and operators to resist agricultural risks.

\section{Conflicts of Interest}

The authors declare no conflicts of interest regarding the publication of this paper. 


\section{References}

[1] Zhang, H.Y., Zhang, H.Y., Li, W.Y. and Li, G.Y. (2015) Agricultural Modernization with Chinese Characteristics: Target Orientation, Reform and Innovation. Chinese Rural Economy, 1, 4-13.

[2] Wang, Y.Z. (2014) The Development of Modern Agriculture in China Should Attach Importance to the Schultz Model. Issues in Agricultural Economy, 2, 41-44.

[3] Zhang, D.P. and Huang, Z.H. (2012) The Perspective on the Relations of Agricultural Modernization's Process and Agricultural Science and Technology. Chinese Rural Economy, 11, 48-53.

[4] Niu, R.F. (2001) How Path to Chinese Agricultural Modernization. Chinese Rural Economy, 1, 4-11.

[5] Wang, Y.P., Lv, M., Fan, J.N. and Wen, Q. (2015) Characteristics, Problems, and Optimized Paths of the Construction of China's Modern Agricultural Science and Technology Innovation System. Research of Agricultural Modernization, 36, 161-167.

[6] Li, M., Li, S.F. and Ouyang, Y.H. (2014) Evaluation on the Development Level of Modern Agriculture of Zhuolu County Based on Entropy Weight. Journal of China Agricultural University, 19, 236-243.

[7] Guo, Y.J., Gao, S.B., Wu, H.J., Liu, Z.W., Wu, W.L. and Zhang, J.L. (2008) Evaluation Method of Integrated Development of Urban Modern Agriculture. Chinese Journal of Eco-Agriculture, 16, 495-501. https://doi.org/10.3724/SP.J.1011.2008.00495

[8] Jiang, H.P., Zhang, C.L. and Liu, X.Y. (2015) Evaluation on the Development Level of Beijing's Urban Modern Agriculture. Research of Agricultural Modernization, 36, 327-332.

[9] Xin, L. and Wang, J.M. (2014) Evaluation on Agricultural Modernization Level of China's Counties-Based on Empirical Analysis of Nationwide 1980 Counties. Research of Agricultural Modernization, 35, 673-678.

[10] Yu, E.S. and Li, H. (2015) Research on Main Management Body of Modern Agriculture in the Two Plains of Heilongjiang Province. Chinese Journal of Agricultural Resources and Regional Planning, 36, 46-52.

[11] Gou, L.F., Gao, Q. and Wang, Y.T. (2015) Research on the Influencing Factors of Agricultural Technology Adoption: An Empirical Study on the New Agricultural Management Entities. Journal of China Agricultural University, 20, 237-244.

[12] Song, H.M., Yu, L. and Shan, Z.F. (2014) Classified Training of Talents in Agricultural Science and Technology for Modern Agriculture Development Problems and Countermeasures. Journal of Nanjing Agricultural University (Social Sciences Edition), 14, 120-125.

[13] Chen, Y.J., Zhang, P.Y., Liu, S.W. and Tan, J.T. (2016) The Spatio-Temporal Pattern Change and Optimum Layout of Grain Production in the West of Northeast China. Scientia Grographica Sinica, 36, 1397-1407.

[14] Wang, F., Liu, Y.F., Kong, X.S., Chen, Y.Y. and Pan, J.W. (2018) Spatial and Temporal Variation of Grain Production and Its Influencing Factors at the County Level in China. Economic Geography, 38, 142-151.

[15] Yuan, H.B. (2017) A Study on Cultivated Land Quality Protection and Agricultural Sustainable Development in the Main Grain Producing Areas of Northeast China. Economic Review, 11, 106-111.

[16] Zhao, H.B. and Ma, Y.J. (2014) Spatial-Temporal Pattern and Obstacle Factors of Cultivated Land Ecological Security in Major Grain Producing Areas of Northeast 
China: A Case Study in Jilin Province. Chinese Journal of Applied Ecology, No. 2, 515-524.

[17] Li, X.Y., Zhao, G.M. and Li, B.Y. (2010) Analysis of Changing Situation of Land Resources in Northeast China. Research of Soil and Water Conservation, No. 5, 68-74.

[18] Quan, Y. and Zheng, C. (2016) Nonlinear Relationship between the Inflation and International Grain Price Based on STR Model. Chinese Journal of Agricultural Resources and Regional Planning, 37, 116-123.

[19] He, X.L. and Liu, W.X. (2012) The Assessment and Policy Simulation of Grain Security of Northeast China. Research of Agricultural Modernization, 33, 678-681.

[20] He, X.L. and Liu, W.X. (2017) Construction and Spatial Layout of Commercial Grain Bases in Northeast China. Chinese Agricultural Science Bulletin, 33, 159-164.

[21] Song, G. and Lin, T. (2016) Research on the Price Mechanism for Use Rights Scale Transfer of Agricultural Land in Northeast Major Grain Producing Region: Taking Keshan as an Example. China Land Sciences, 30, 44-51.

[22] Huang, X.X., An, P.L., Cai, L.J., Wang, F.T., Li, S. and Li, X.M. (2015) Self-Development Abilities of Farmers in the Northeast Grain Production Area of China. Resources Science, 37, 1825-1833. 